\title{
A Method for the Estimation of Urinary Testosterone
}

\author{
By A. A. A. ISMAIL AND R. A. HARKNESS \\ Medical Research Council Clinical Endocrinology Research Unit, University of Edinburgh
}

(Received 3 December 1965)

\begin{abstract}
1. A method has been developed for the estimation of testosterone in human urine by using acid hydrolysis followed by a quantitative form of a modified Girard reaction that separates a 'conjugated-ketone' fraction from a urine extract; this is followed by column chromatography on alumina and paper chromatography. 2. Comparison of methods of estimation of testosterone in the final fraction shows that estimation by gas-liquid chromatography is more reproducible than by colorimetric methods applied to the same eluates from the paper chromatogram. 3. The mean recovery of testosterone by gas-liquid chromatography is $79.5 \%$, and this method appears to be specific for testosterone. 4. The procedure is relatively rapid. Six determinations can be performed by one worker in 2 days. 5. Results of determinations on human urine are briefly presented. In general, they are similar to earlier estimates, but the maximal values are lower.
\end{abstract}

Testosterone (17 $\beta$-hydroxyandrost-4-en-3-one) is the most potent androgen that has been isolated from natural sources. Although it is metabolized to 17-oxo steroids, the estimation of these compounds in the urine is rarely useful in the assessment of androgen production because the principal precursors of the 17-oxo steroids are only weakly androgenic.

Schubert \& Wehrberger (1960) isolated testosterone from a large number of pooled urine samples from normal men. Since then several methods have been described for the estimation of this hormone in urine and such methods do provide a reasonably satisfactory index of androgen production (Vander Wiele, McDonald, Gurpide \& Lieberman, 1963; Horton, Shinsako \& Forsham, 1965).

The published methods (see the references in Table 3) for the estimation of testosterone in urine have disadvantages. Some methods require the use of radioactive testosterone either for the location of the testosterone fraction in a chromatographic procedure or to calculate the recovery. Some procedures do not completely separate testosterone and its $17 \alpha$-epimer, epitestosterone, which is not derived from the hormone (Brooks \& Giuliani, 1964). Others require large volumes of urine. In addition, many of these methods involve numerous or complicated chromatographic separations.

The present paper describes a method that avoids many of the disadvantages associated with previously described procedures. A preliminary account has been published (Ismail \& Harkness, 1965). After hydrolysis of the urine and subsequent extraction of the free steroids, a 'conjugatedketone' fraction containing testosterone was separated from this extract by using a modified Girard reaction. This purification step allows acid hydrolysis to be employed and also simplifies the subsequent procedures necessary to obtain a pure fraction containing the hormone. Further simple chromatography on alumina and on paper provides a reasonably pure sample of testosterone. The compound may then be determined by a colour reaction or by gas-liquid chromatography. The reliability criteria of the method are assessed. Some preliminary results obtained in normal subjects are briefly presented.

\section{MATERIALS AND METHODS}

Reagents and solvents. The solvents and reagents used were of analytical-grade quality in all cases in which this grade was available. The solvents were redistilled before use. Girard reagent $T$ was washed with ethanol. The cationexchange resin Amberlite IRC-50 ( $\mathbf{H}^{+}$form) (British Drug Houses, Ltd., Poole, Dorset, and Rohm and Haas Co., Philadelphia, Pa., U.S.A.) was washed three times in 10-20g. batches with warm aq. $5 \%(v / v) \mathrm{H}_{2} \mathrm{SO}_{4}$; the resin was then washed with water until the washings were neutral. It was stored with a small quantity of water.

Paper and thin-layer chromatography. Paper chromatography was performed on Whatman no. 42 paper in the system toluene-light petroleum (b.p. 60-80 $)$-methanolwater (33:66:80:20, by vol.). Chromatograms were inspected under ultraviolet light (wavelength approx. $250 \mathrm{~m} \mu$ ) and then treated with either Zimmermann reagent, $8 \%(w / v)$ phosphomolybdic acid in ethanol, or a saturated ethanolic solution of dinitrophenylhydrazine acidified with a few drops of conc. HCl. Paper chromatograms were run automatically overnight after at least $4 \mathrm{hr}$. equilibration. An alarm clock was modified to turn a tap that filled the trough with solvent. Thin-layer chromatography was performed on silica gel $G$ spread in sheets approx. $250 \mu$ thick. 
After spreading, the coated plates were heated at $100^{\circ}$ for $30 \mathrm{~min}$. and then stored in a desiccator until required. The systems chloroform-ethyl acetate $(2: 1, v / v)$ and benzeneethyl acetate $(3: 2$ and $3: 1, v / v)$ were employed. In addition to the methods of detection described above for paper chromatograms, thin-layer plates were treated with $0.5 \%$ $(\mathrm{w} / \mathrm{v})$ vanillin in ethanol-conc. $\mathrm{H}_{2} \mathrm{SO}_{4}(1: 4, \mathrm{v} / \mathrm{v})$.

Alumina column chromatography. Column chromatography was carried out in glass tubes with an internal diameter of $0.5 \mathrm{~cm}$. and with taps at the lower ends. The packing was supported on a small plug of cotton wool placed at the lower end of the tubes. The alumina used (100-240 mesh, alkaline; Hopkin and Williams Ltd., Chadwell Heath, Essex) had a Brockmann activity of $I$; this was reduced by the addition of about $10 \%(\mathrm{v} / \mathrm{w})$ of water which was then thoroughly mixed with the alumina. The activity of the alumina was adjusted by the stepwise addition of more water so that, when testosterone was applied to a $6 \cdot 0 \mathrm{~cm}$. $\times$ $0.5 \mathrm{~cm}$. column of alumina in benzene in $5 \mathrm{ml}$. of the same solvent followed by $10 \mathrm{ml}$. of $0 \cdot 15 \%(\mathrm{v} / \mathrm{v})$ ethanol in benzene, the steroid began to be eluted after approx. $4 \mathrm{ml}$. of $0.3 \%$ $(v / v)$ ethanol in benzene had been passed through the column. All the testosterone should appear in the next $7 \mathrm{ml}$. of eluate.

Gas-liquid chromatography. Gas-liquid chromatography was performed in a Pye Panchromatograph with a flame ionization detector. All-glass columns $150 \mathrm{~cm} . \times 0.4 \mathrm{~cm}$. were used. The apparatus for the introduction of the sample into the column and its mode of operation were those described by Menini \& Norymberski (1965). The columns were packed with silicone-treated Gas Chrom P (100-120 mesh) coated with $1 \%$ (w/w) SE-30 or QF-1 as described by Brooks \& Hanaineh (1963). Nitrogen flow was $30 \mathrm{ml} . / \mathrm{min}$., and the column temperature was $220^{\circ}$ for SE-30 and $205^{\circ}$ for QF-1. The evaporation chamber was kept at least $20^{\circ}$ above the column operating temperature. The flame ionization detector was used at the optimum conditions determined by Fowlis, Maggs \& Scott (1964). The quantity of steroid in the extract was estimated from the peak height by using a corresponding external standard.

Determination of radioactivity and spectroscopy. Radioactivity due to ${ }^{14} \mathrm{C}$ was measured by liquid-scintillation counting by using the method described by Harkness \& Fotherby (1963). Absorption spectra were recorded in a Unicam SP.800 spectrophotometer for the visible and ultraviolet region and in a Perkin-Elmer 237 spectrophotometer for the infrared region of the spectrum from wavelengths 2.5 to $16 \cdot 0 \mu$. For infrared spectroscopy specimens were dissolved in carbon disulphide (for spectroscopy; British Drug Houses Ltd.) and placed in a cell with a $0.5 \mathrm{~mm}$. light-path. In the visible and ultraviolet region a $1 \mathrm{~cm}$. light-path was used.

Preparation of urine extracts. Complete $24 \mathrm{hr}$. collections of urine were made and stored at $4^{\circ}$. Specimens of volume less than $1200 \mathrm{ml}$. were made up to that volume with water. Enzymic hydrolysis was performed by the method described by Harkness \& Fotherby (1963). The conditions chosen were a concentration of 1000 units of $\beta$-glucuronidase $/ \mathrm{ml}$. The urine was incubated at $37^{\circ}$ for $48 \mathrm{hr}$. Acid hydrolysis was performed by boiling the urine under reflux condensers after the addition of acid. After hydrolysis, the urine was extracted with ether. The extract was evaporated to dryness. Although benzene might have been expected to yield cleaner extracts, it led to considerable emulsion formation.
Modified Girard separation. The residue was dissolved in $1.0 \mathrm{ml}$. of $97 \%(\mathrm{v} / \mathrm{v})$ ethanol, and 150-200 mg. of Amberlite IRC-50 and 300-500 mg. of Girard reagent T were added. The mixture was then refluxed for $1 \mathrm{hr}$., cooled and mixed with $10 \mathrm{ml}$. of water. The solution was decanted and was extracted once with 1 vol. and twice with 0.5 vol. of ethyl acetate. After each extraction, the upper phase was removed by suction. A $9.5 \mathrm{ml}$. sample was then taken from the aqueous phase and $2.0 \mathrm{ml}$. of aq. $36 \%(\mathrm{w} / \mathrm{v})$ formaldehyde was added. The solution was left on the bench overnight and was extracted three times with $12 \mathrm{ml}$. of ethyl acetate to obtain the formaldehyde-labile 'conjugated-ketone' fraction containing testosterone. The combined ethyl acetate extracts were washed six times with $5 \mathrm{ml}$. of water and were dried with anhydrous $\mathrm{Na}_{2} \mathrm{SO}_{4}$. A $32 \mathrm{ml}$. sample was evaporated to dryness under reduced pressure in a water bath at $70^{\circ}$. The last traces of formaldehyde were removed with a jet of air.

Standard analytical procedure. A flow sheet for the present method is shown in Scheme 1.

(a) Hydrolysis and extraction. Samples of volume $50 \mathrm{ml}$. of male urine and of volume $200 \mathrm{ml}$. of female urine were used for each determination. The method of choice for routine assays was hydrolysis by boiling for $1 \mathrm{hr}$. with $0.15 \mathrm{vol}$. of conc. HCl. After hydrolysis, the urine was cooled and extracted twice with 1 vol. of ether. The combined ether extracts were washed twice with 0.05 vol. of $\mathrm{N}-\mathrm{NaOH}$ saturated with $\mathrm{NaCl}$. This was usually sufficient to remove the yellow pigments. Occasionally a third wash was necessary. The extract was then washed three times with 0.05 vol. of water. The ether extract was dried with anhydrous $\mathrm{Na}_{2} \mathrm{SO}_{4}$ and evaporated to dryness on a water bath. The residue was then dissolved in $5.5 \mathrm{ml}$. of $97 \%(\mathrm{v} / \mathrm{v})$ ethanol and a $5.0 \mathrm{ml}$. sample was transferred to a B 14 tube. The sample was concentrated to a volume of $1.0 \mathrm{ml}$. or to dryness in a current of air. The Girard separation was then performed by the modified method described above.

(b) Chromatography. The 'conjugated-ketone' fraction was dissolved in $5 \mathrm{ml}$. of benzene and applied to a $6.0 \mathrm{~cm} . \times$ $0.5 \mathrm{~cm}$. column of alumina in benzene. The column was eluted with $10 \mathrm{ml}$. of $0.15 \%(\mathrm{v} / \mathrm{v})$ ethanol in benzene, which was discarded. The fraction containing testosterone was eluted with $15 \mathrm{ml}$. of $0.3 \%(v / v)$ ethanol in benzene. This eluate was evaporated to dryness and the residue applied to paper. The paper was chromatographed in the system described above. Authentic testosterone was chromatographed in parallel with the extracts and located by its absorption of ultraviolet light. The areas of the chromatograms of the extracts corresponding to testosterone were then eluted with ethanol. The eluate was then filtered through sintered glass and a sample was evaporated to dryness. The residue was then subjected to gas-liquid chromatography or to oxidation with $\mathrm{CrO}_{3}$. Oxidation was carried out by dissolving the residue in $0.2 \mathrm{ml}$. of acetic acid and adding $0.2 \mathrm{ml}$. of freshly prepared aq. $15 \%(\mathrm{w} / \mathrm{v}) \mathrm{CrO}_{3}$. The solution was kept in the dark at $25^{\circ}$ for 15 min. Then $3 \mathrm{ml}$. of aq. $8 \%(w / v)$ sodium citrate was added. The oxidation products were extracted with $10 \mathrm{ml}$. of chloroform, which was washed once with $1 \mathrm{ml}$. of aq. $0 \cdot 1 \mathrm{~N}-\mathrm{NaOH}$ and twice with $1 \mathrm{ml}$. of water. The extract was then dried with anhydrous $\mathrm{Na}_{2} \mathrm{SO}_{4}$ and a sample was evaporated to dryness. Gas-liquid chromatography or the micro-Zimmermann reaction was then performed. The latter reaction was carried out by dissolving the residue in $0.1 \mathrm{ml}$. of freshly 
Samples of $24 \mathrm{hr}$. urine (200 ml. of female urine;

$50 \mathrm{ml}$. of male urine)

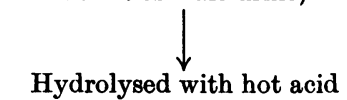

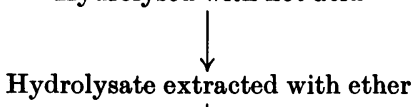

Ether extract washed with $\mathrm{N}-\mathrm{NaOH}$ saturated with $\mathrm{NaCl}$, then with water (washings discarded)

Ether extract dried with $\mathrm{Na}_{2} \mathrm{SO}_{4}$ and evaporated to dryness

Residue subjected to Girard separation, with Amberlite IRC-50 as catalyst and aq. formaldehyde as hydrolysing agent: 'conjugated-ketone' fraction

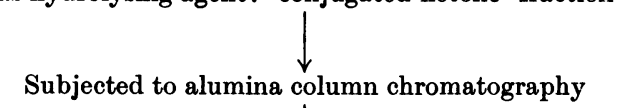

Subjected to alumina column chromatography

Eluate subjected to paper chromatography

(light petroleum-toluene-methanol-water)

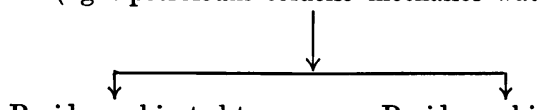

Residue subjected to $\longrightarrow$ Residue subjected to
$\mathrm{CrO}_{3}$ oxidation $\longrightarrow$ gas-liquid chromatography

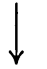

Subjected to

micro-Zimmermann

reaction

Scheme 1. Outline of the present method for the measurement of testosterone in urine.

prepared $0.5 \%(w / v) m$-dinitrobenzene in ethanol and adding $0.1 \mathrm{ml}$. of aq. $20 \%(\mathrm{w} / \mathrm{v})$ tetraethylammonium hydroxide. The solution was kept at $0-4^{\circ}$ for $3 \mathrm{hr}$. The reaction mixture was then diluted with $0.5 \mathrm{ml}$. of ethanol and with a similarly treated reagent blank the extinctions were measured at 432,512 and $592 \mathrm{~m} \mu$. The results were corrected by the method of Allen (1950). Gas-liquid chromatography was carried out on a column coated with QF-1. External standards of the relevant steroid were used to estimate retention times and peak heights for a given weight of steroid. The results were corrected for the samples taken during the procedure and for the overall recovery.

\section{RESULTS}

\section{Hydrolysis}

Previous methods for the determination of testosterone in urine have used enzymic hydrolysis with various $\beta$-glucuronidase preparations (see the
Table 1. Comparison of hot-acid and enzymic hydrolysis used for the release of urinary testosterone

Experimental details are given in the text.

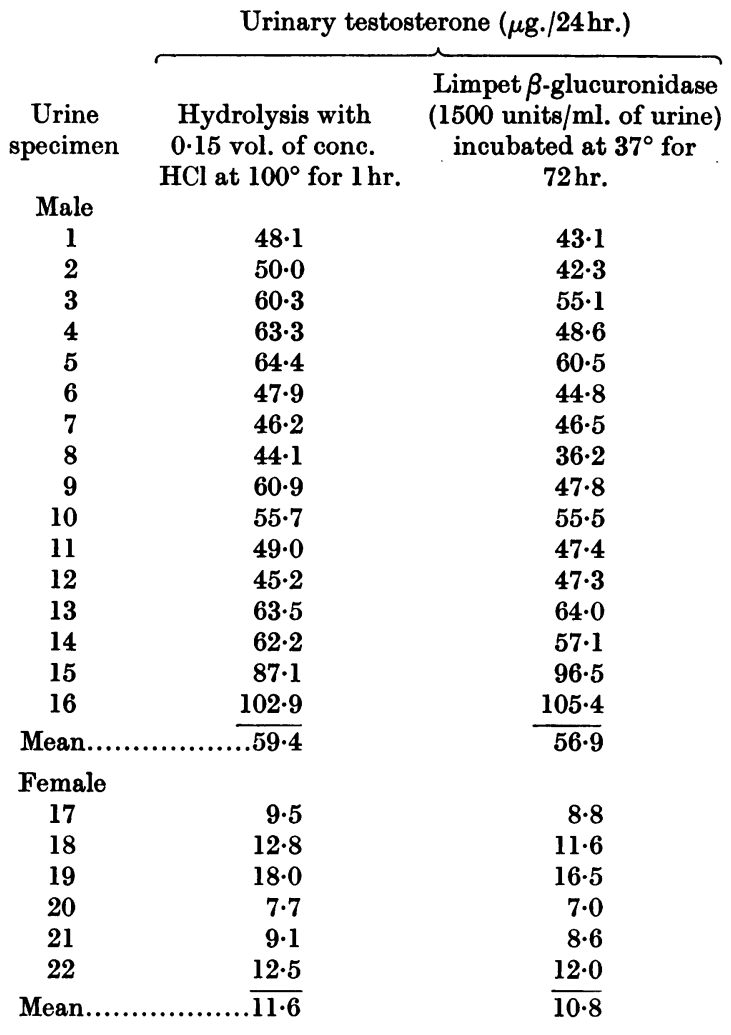

references in Table 3). Most workers have incubated at $37^{\circ}$ for $48 \mathrm{hr}$. with different concentrations of this enzyme. In the present work, incubation at $37^{\circ}$ for $48 \mathrm{hr}$. with a concentration of 1000 units of $\beta$-glucuronidase activity $/ \mathrm{ml}$. was found to give reproducible results. With longer periods of incubation or with higher concentrations of enzyme activity the increase in the amount of testosterone released was only $5-10 \%$. Most of the testosterone was released by incubation for $18 \mathrm{hr}$. with a concentration of only 500 units $/ \mathrm{ml}$.

In the present study, it was possible to use acid hydrolysis; the amounts of testosterone recovered from the same urine specimen after acid and after enzymic hydrolysis were similar (Table 1). In an attempt to ensure complete hydrolysis with the enzyme preparation, a higher concentration and longer period of incubation were used in the comparison with acid hydrolysis. However, the urine specimens numbered 4, 8 and 9 showed lower yields of testosterone after enzymic hydrolysis; the urinary excretion of testosterone was $48 \cdot 6,36 \cdot 2$ and 
$47 \cdot 8 \mu \mathrm{g} \cdot / 24 \mathrm{hr}$. respectively. The endogenous inhibitor of $\beta$-glucuronidase in these urine specimens was destroyed by treatment with alkali (Harkness \& Fotherby, 1963; Marsh, 1963) and enzymic hydrolysis was repeated. The repeat estimates of urinary testosterone were $61 \cdot 2,36 \cdot 8$ and $45 \cdot 0 \mu \mathrm{g} . / 24 \mathrm{hr}$. respectively. From the results on urine specimen 4 it is possible that one cause of the difference in effectiveness between acid and enzyme hydrolysis is the endogenous inhibitor of $\beta$-glucuronidase in urine, glucaro-( $1 \rightarrow 4$ )-lactone (Marsh, 1963). Conditions for hot-acid hydrolysis were studied. When the urine was boiled for $1 \mathrm{hr}$. much less contamination was observed in the final extract and the amount of testosterone recovered was also greater than when the urine was boiled for 15 or $30 \mathrm{~min}$. The stability of testosterone under the conditions of acid hydrolysis was confirmed. A $5 \mu \mathrm{g}$. sample of authentic testosterone was added to $200 \mathrm{ml}$. of water and boiled for $1 \mathrm{hr}$. with 0.15 vol. of concentrated hydrochloric acid. In six experiments the mean amount of testosterone recovered by ether extraction, as estimated by gas-liquid chromatography, was $96 \cdot 8 \pm 2.0 \%$ (s.D.). In these experiments no artifacts from testosterone were detected. However, acid hydrolysis of urine produced small amounts of compounds that were not detected in gas-liquid chromatograms when enzyme hydrolysis was used (Fig. 1).

\section{Girard separation}

When the modifications of the Girard reaction described by Taylor (1958) and by Lindner (1960) were used with urine extracts, low recoveries of testosterone were obtained. In the present study, increased amounts of Girard reagent $T$ and of Amberlite IRC-50 were found to be necessary to achieve high and reproducible recoveries with small amounts of steroids in relatively large amounts of residue. It was also necessary to activate the Amberlite IRC-50 by washing with dilute acid (Astle, 1957). In a series of 12 experiments, $20 \mu \mathrm{g}$. of testosterone was subjected to the present modification and $93 \pm 2.3 \%$ (mean \pm S.D.) was recovered in the formaldehyde-labile fraction.

\section{Chromatography}

Alumina column chromatography. The Girard separation as modified in the present study was found to remove a great many contaminants from the urine extracts. Nevertheless, the residue was still bulky in most samples after acid hydrolysis; the residues were generally large for direct application to paper or to thin-layer plates. Chromatography of the residue on an alumina column was found to give, in all cases, a testosterone fraction suitable for application to paper. However, after enzymic hydrolysis of the urine of normal men, the 'conjugated-ketone' fraction could be applied easily to paper or to thin-layer plates.

Paper and thin-layer chromatography. When the testosterone fraction from the alumina column was chromatographed on thin layers of silica gel in the three different systems described above, five spots could be detected with vanillin in ethanolic sulphuric acid. Testosterone was not clearly separated from other closely related compounds, especially epitestosterone. However, paper chromatography in the system described above clearly separated testosterone from epitestosterone and other closely related compounds in the extract. Extracts from 20 different male and female urines were examined in this paper-chromatographic system by using all the methods of detection described above. Only five spots could be detected and these were well separated. The separations achieved in the chromatographic systems A and B3 (Bush, 1952) were less satisfactory.

\section{Methods of detection and oxidation}

Colour reaction for testosterone. In the present work, it was necessary to measure small quantities of testosterone accurately. For this a sensitive and simple method was needed. The absorption of ultraviolet light by testosterone in ethanol and in sulphuric acid was affected by impurities, and the Koenig colour reaction (Koenig, Melzer, Szego \& Samuels, 1941) was laborious. A colour reaction was developed that is somewhat similar to those described by Koenig et al. (1941) and others. A solution of $0.5 \%$ vanillin in ethanol-sulphuric acid $(1: 4, v / v)$ is a highly sensitive reagent for the detection of steroids on thin-layer chromatograms. The intense yellow colour of this reagent in solution only showed a slight change when $10 \mu \mathrm{g}$. of testosterone was added and the solution was heated. Decreasing the concentration of vanillin to $0.05 \%$ $(w / v)$ did not diminish the colour in the reagent blank and there was little change in the colour after the addition of testosterone. However, after incubation for $17 \mathrm{hr}$. at $25^{\circ}$, dilution of the reaction mixture with 2 vol. of water caused the colour of the reagent blank to disappear and a bluish-violet colour developed in the presence of testosterone, epitestosterone and androstenedione (androst-4ene-3,17-dione). The colour obtained with testosterone was approximately twice that from epitestosterone and androstenedione. The absorption of visible light was maximal at $595 \mathrm{~m} \mu$; no other maxima were found between 400 and $700 \mathrm{~m} \mu$. No appreciable colour was produced with $3 \alpha$-hydroxy$5 \alpha$-androstan-17-one, $3 \alpha$-hydroxy - $5 \beta$-androstan-17one, 3 $\beta$-hydroxyandrost-5-en-17-one, pregn-4-ene- 
3,20 - dione, $3 \beta$ - hydroxypregn - 5 - en - 20 - one, $5 \beta$-pregnane-3 $\alpha, 20 \alpha$-diol, $5 \beta$-pregnane-3 $\alpha, 17 \alpha, 20 \alpha$ triol, $11 \beta, 17 \alpha, 21$ - trihydroxypregn - 4 - ene - 3,20 dione and $17 \alpha, 21$-dihydroxypregn-4-ene-3,11,20trione. Further, $0 \cdot 3 \mu \mathrm{g}$. of testosterone in a total volume of $0.5 \mathrm{ml}$. of reagent diluted in this way gave an extinction value of 0.060 when corrected by the method of Allen (1950) by using readings at 510, 595 and $680 \mathrm{~m} \mu$. This colour reaction was employed for the standardization of the alumina used in column chromatography. In addition, this procedure was employed in the estimation of testosterone in a sample of pooled male urine. The mean of six replicates was $49 \cdot 7 \mu \mathrm{g}$. $/ 24 \mathrm{hr}$. The standard deviation was $\pm 8.0 \mu \mathrm{g} . / 24 \mathrm{hr}$. The mean of six determinations by gas-liquid chromatography was $56.5 \mu \mathrm{g} . / 24 \mathrm{hr}$., and the standard deviation was $\pm 3 \cdot 6 \mu \mathrm{g} . / 24 \mathrm{hr}$. This latter standard deviation is on the borderline of being significantly lower than that for the colorimetric procedure. The mean values obtained by this procedure are not significantly different. The oxidation of testosterone to androstenedione allowed the sensitive micro-Zimmermann reaction to be used. In the Zimmermann reaction the chromogenicity of androstenedione was approximately equal to the sum of the colours produced by $3 \alpha$-hydroxy-5 $\alpha$-androstan-17-one and testosterone. Low blank values were obtained by developing the colour at $0-4^{\circ}$ and using tetraethylammonium hydroxide as an organic base. The development of the colour at higher temperatures or with other bases produced higher blank values. Extraction of the Zimmermann colour did not improve the results.

Conditions for the oxidation of testosterone with chromium trioxide were adjusted to give the optimum yield of androstenedione without appreciable formation of artifacts ; different times, temperatures and concentrations of chromium trioxide were investigated. The procedure described by Menini \& Norymberski (1962) was also found to be satisfactory but required $2 \mathrm{hr}$. instead of $15 \mathrm{~min}$. for oxidation. In a series of 30 experiments with the conditions described above the mean recovery ( \pm S.D.) of androstenedione from $5 \mu \mathrm{g}$. of testosterone was $92 \pm 3.0 \%$.

Gas-liquid chromatography. Initially a column coated with $1 \%$ SE-30 was used. However, impurities from solvents and urine have retention times similar to those of the steroids under consideration. A column coated with $1 \%$ QF-1 provided much better separations. The impurities from urine extracts, solvents and reagents had shorter retention times than those of the steroids and thus did not interfere with their determination. The use of a column coated with QF-1 produced a smooth base line from which the height of the peaks due to testosterone and androstenedione could be

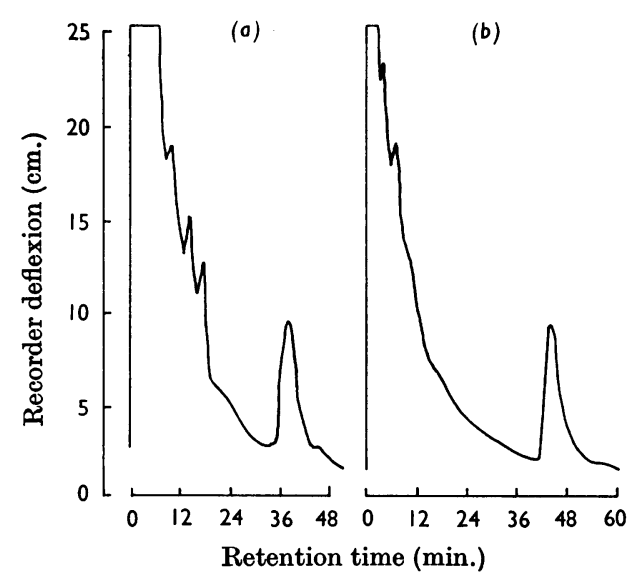

Fig. 1. Gas-liquid chromatogram on a column coated with $1 \%(w / w)$ QF-1 of an extract obtained by the present method from a female urine, after oxidation of the testosterone to $0 \cdot 1 \mu \mathrm{g}$. of androstenedione: $(a)$ after acid hydrolysis; (b) after enzyme hydrolysis.

measured. Extracts from male urine could always be chromatographed as testosterone. However, in low-titre female urine oxidation of testosterone to androstenedione ensured that the peak appeared on a reasonably flat base line. A further advantage was the large difference in retention time between testosterone and androstenedione; oxidation of the extract and further gas-liquid chromatography provided a check on the specificity of the determination. The extracts used to obtain the tracings shown in Fig. 1 contained a large amount of contaminants and little testosterone; most fresh urine specimens from both men and women contained much less interfering material. It should be noted that the impurities produced by acid hydrolysis were only slightly greater than those after enzymic hydrolysis.

\section{Reliability criteria of the method}

Accuracy. This was estimated on the basis of recovery experiments. A $20 \mu \mathrm{g}$. sample of unlabelled testosterone was added to $200 \mathrm{ml}$. of water and $0 \cdot 01 \mu \mathrm{g}$. of $\left[4^{-14} \mathrm{C}\right]$ testosterone was added to $400 \mathrm{ml}$. of female urine. The recoveries obtained with different methods of detection are shown in Table 2. Estimates of about $70-80 \%$ were obtained by using gas-liquid chromatography and by counting the radioactive testosterone. However, the recoveries obtained by using the microZimmermann colour reaction were only about $50-60 \%$.

Precision. The precision of a method may be 
Table 2. Accuracy of the method used for determining urinary testosterone

Experimental details are given in the text. The numbers of observations are given in parentheses.

\author{
Method of detection \\ Radioactivity due to \\ [4-14C]testosterone \\ Gas-liquid chromatography \\ as testosterone \\ Gas-liquid chromatography \\ as androstenedione \\ Micro-Zimmermann reaction \\ after oxidation to \\ androstenedione
}

\author{
Amount of testosterone added \\ after hydrolysis $(\mu \mathrm{g}$. \\ 0.01
}

$20 \cdot 0$

$20 \cdot 0$

$20 \cdot 0$

\author{
Mean percentage \\ recovery \pm S.D. \\ $81 \cdot 4 \pm 5 \cdot 2(12)$ \\ $79 \cdot 5 \pm 4 \cdot 5(12)$ \\ $72 \cdot 3 \pm 4 \cdot 2(11)$ \\ $57 \cdot 2 \pm 11 \cdot 6(10)$
}

estimated from the difference between duplicate assays (see Snedecor, 1952). From male urine, the standard deviation from 28 pairs of estimates was $\pm 3.2 \mu \mathrm{g}$. for a mean of $50.0 \mu \mathrm{g}$. $/ 24 \mathrm{hr}$. In 29 pairs of estimates from female urine the standard deviation was $\pm 0.75 \mu \mathrm{g}$. for a mean of $9.4 \mu \mathrm{g} . / 24 \mathrm{hr}$. The coefficients of variation were $6.4 \%$ and $8 \%$ for male and female urine respectively, indicating that the present method is reasonably precise.

Specificity. The identity of the compound estimated in the present method was examined in several different ways. Thin-layer chromatography of the eluate from the area of paper chromatograms corresponding to testosterone showed only one component when the plates were sprayed with vanillin in ethanolic sulphuric acid or with phosphomolybdic acid in ethanol. In 60 chromatograms from different samples of male and female urine only one spot could be detected, corresponding in colour and position to testosterone. Oxidation of 30 residues obtained from different paper chromatograms produced a compound identical with androstenedione both in thin-layer chromatograms and in gas-liquid chromatography on columns coated with QF-1 and SE-30. In 12 experiments, formation of the acetate of the compound in the final eluate from paper gave a substance of the same mobility as authentic testosterone acetate in thin-layer chromatography and the same retention time in gas-liquid chromatography on columns coated with SE-30 and QF-1. The latter system is capable of partially separating testosterone acetate from epitestosterone acetate (Brooks, 1964). Spectroscopic investigations were carried out on the final extracts from male urine. The infrared spectrum of the substance obtained after the paper-chromatographic procedure in the present method was similar to that of authentic testosterone. There was some interference in the 'carbonyl stretching zone', which was greatly decreased by further thin-layer chromatography. The absorption spectrum of the eluate from paper in sulphuric acid and the colour reaction with vanillin in ethanolic sulphuric acid described above were identical with those of authentic testosterone. Testosterone could not be detected in 12 urine samples from a woman subjected to bilateral adrenalectomy and ovariectomy and accordingly it was concluded that the non-steroidal materials present in the patient's urine did not interfere with the method.

Sensitivity. About $0.5 \mu \mathrm{g}$. of androstenedione could be measured in the final residue with fair accuracy by using the micro-Zimmermann reaction and $0 \cdot 1 \mu \mathrm{g}$. by gas-liquid chromatography. The sensitivity calculated according to the method employed by Brown, Bulbrook \& Greenwood (1957) was $0.5 \mu \mathrm{g}$. in a $24 \mathrm{hr}$. collection of urine $(P 0.05)$.

Practicability. It has been found that six determinations can be performed by a technician in 2 working days. The present method is therefore similar in length to that of Brown (1955) for urinary oestrogens.

\section{Urinary excretion of testosterone in normal subjects}

In general the urinary excretion of testosterone was higher in young men than in the older age group. In 80 determinations from 20 normal males aged 21-63 years, the mean excretion of testosterone was $51 \cdot 7 \mu \mathrm{g} . / 24 \mathrm{hr}$. (range $40 \cdot 0-64 \cdot 5 \mu \mathrm{g}$. $/ 24 \mathrm{hr}$.). In 15 determinations from five young men aged 16-20 years, the mean excretion was $78 \cdot 0 \mu \mathrm{g}$. $/ 24 \mathrm{hr}$. (range $60 \cdot 0-103 \cdot 0 \mu \mathrm{g} . / 24 \mathrm{hr}$.$) .$

The mean excretion in 45 determinations from 15 women aged $20-55$ years was $6.5 \mu \mathrm{g}$. $/ 24 \mathrm{hr}$. (range 2.1-10.7 $\mu \mathrm{g} . / 24 \mathrm{hr}$.). Thus there was a marked difference between the amounts excreted in male and female urine. Tables 3 and 4 show the urinary excretion of testosterone measured by different methods. The present method gave values that are in agreement with the results of some of these previous methods. However, the upper limits of the results obtained with the present method were 
generally lower than those of some of the previous methods.

\section{DISCUSSION}

The evidence obtained by gas-liquid chromatography (Fig. 1) shows that testosterone is the major steroid component in the final extract. The more efficient separation of testosterone from contaminants and closely related steroids on the selective polar phase QF-1 was also shown by Sandberg et al. (1964). The main reason for the more efficient separation was that most contaminants from the materials used in the method had very short retention times on a column coated with QF-1.

Two other steroids that may be present in biological material, namely androst-4-ene-3,11,17trione (adrenosterone) and 17 $\alpha$-hydroxypregn-4ene-3,20-dione (17 $\alpha$-hydroxyprogesterone), behave chromatographically on paper in the same way as testosterone (Cathro, Cameron \& Birchall, 1965). Adrenosterone was clearly separated from testosterone and androstenedione by gas-liquid chromatography on a column coated with the phase QF-1. When $17 \alpha$-hydroxyprogesterone was subjected to gas-liquid chromatography under the conditions used in the present investigation no compound could be detected in the effluent. This steroid, if present in urine, would probably be destroyed by acid hydrolysis (Dorfman \& Shipley, 1956). However, this compound would be oxidized with chromium trioxide to androstenedione. The $17 \alpha$-epimer, epitestosterone, is not completely separated from

Table 3. Urinary testosterone excretion by normal men as estimated by different methods

\begin{tabular}{|c|c|c|c|c|}
\hline \multirow{2}{*}{$\begin{array}{c}\text { Age } \\
\text { (years) }\end{array}$} & \multirow{2}{*}{$\begin{array}{c}\text { No. of } \\
\text { subjects }\end{array}$} & \multicolumn{2}{|c|}{$\begin{array}{l}\text { Urinary testosterone } \\
(\mu \mathrm{g} . / 24 \mathrm{hr} .)\end{array}$} & \multirow[b]{2}{*}{ Reference } \\
\hline & & Mean & Range & \\
\hline 23-34 & 5 & $87 \cdot 0$ & $46 \cdot 1-106 \cdot 0$ & Camacho \& Migeon (1963) \\
\hline $23-60$ & 4 & 29.5 & $16 \cdot 0-51 \cdot 0$ & Vermeulen \& Verplancke (1963) \\
\hline $19-55$ & 21 & $113 \cdot 8$ & $38 \cdot 0-291 \cdot 0$ & Futterweit et al. (1963) \\
\hline $29-56$ & 4 & $71 \cdot 5$ & $33 \cdot 0-120 \cdot 0$ & Brooks (1964) \\
\hline 18-22 & 2 & $163 \cdot 0$ & $126-200$ & Ibayashi et al. (1964) \\
\hline $26-62$ & 14 & $95 \cdot 3$ & 14-189 & \\
\hline 27-33 & 12 & $82 \cdot 5$ & $47-140$ & Sandberg et al. (1964) \\
\hline $18-35$ & 5 & 54 & $32 \cdot 0-69 \cdot 0$ & Voigt et al. (1964) \\
\hline $18-44$ & 9 & 34 & $10-75$ & Schubert \& Frankenberg (1964) \\
\hline $21-63$ & 14 & 182.5 & $15 \cdot 1-523 \cdot 3$ & Dulmanis et al. (1964) \\
\hline 30 & 3 & $64 \cdot 3$ & $42 \cdot 0-79 \cdot 0$ & Zurbrügg et al. (1965) \\
\hline $30-40$ & 20 & 88 & $28-143$ & Rosner et al. (1965) \\
\hline $17-24$ & 5 & 151 & $113-193$ & Lim \& Dingman (1965) \\
\hline $18-65$ & 27 & $49 \cdot 7$ & $30 \cdot 2-86 \cdot 3$ & \\
\hline $20-48$ & 9 & 148 & $59 \cdot 0-202 \cdot 0$ & Sparagana (1965) \\
\hline $21-63$ & 20 & $51 \cdot 7$ & $40 \cdot 0-64 \cdot 5$ & Present method \\
\hline $16-20$ & 5 & $78 \cdot 0$ & $60 \cdot 0-103 \cdot 0$ & \\
\hline
\end{tabular}

Table 4. Urinary testosterone excretion by normal women as estimated by different methods

\begin{tabular}{|c|c|c|c|c|}
\hline \multirow{2}{*}{$\begin{array}{c}\text { Age } \\
\text { (years) }\end{array}$} & \multirow{2}{*}{$\begin{array}{l}\text { No. of } \\
\text { subjects }\end{array}$} & \multicolumn{2}{|c|}{$\begin{array}{c}\text { Urinary testosterone } \\
(\mu \mathrm{g} . / 24 \mathrm{hr} .)\end{array}$} & \multirow[b]{2}{*}{ Reference } \\
\hline & & Mean & Range & \\
\hline $19-23$ & 4 & $5 \cdot 9$ & $3 \cdot 5-7 \cdot 5$ & Camacho \& Migeon (1963) \\
\hline 23-37 & 6 & $6 \cdot 1$ & $2 \cdot 8-8 \cdot 0$ & Futterweit et al. (1963) \\
\hline $18-63$ & 4 & $8 \cdot 3$ & $5 \cdot 0-12 \cdot 0$ & Vermeulen \& Verplancke (1963) \\
\hline 21-32 & 4 & 12 & $7 \cdot 0-18 \cdot 0$ & Brooks (1964) \\
\hline 20-72 & 10 & $<5 \cdot 3$ & $<5 \cdot 0-8 \cdot 0$ & Ibayashi et al. (1964) \\
\hline 22-35 & 4 & 10 & $3 \cdot 0-18 \cdot 0$ & Voigt et al. (1964) \\
\hline $21-68$ & 18 & $48 \cdot 9$ & $2 \cdot 9-196 \cdot 7$ & Dulmanis et al. (1964) \\
\hline 29-35 & 2 & $4 \cdot 8$ & $4 \cdot 1-5 \cdot 6$ & Zurbrügg et al. (1965) \\
\hline $20-40$ & 20 & $19 \cdot 0$ & $6-57$ & Rosner et al. (1965) \\
\hline $22-59$ & 16 & $7 \cdot 1$ & $4 \cdot 3-10 \cdot 4$ & Lim \& Dingman (1965) \\
\hline $20-55$ & 15 & 6.5 & $2 \cdot 1-10 \cdot 7$ & Present method \\
\hline
\end{tabular}


testosterone by thin-layer chromatography or gasliquid chromatography, but it can be separated on paper, and can be estimated by subsequent gasliquid chromatography of the extract of the appropriate area of the final paper chromatogram.

There is considerable evidence to show that the present method is specific for testosterone. The compound estimated as testosterone in the present method possesses a 'conjugated-ketone' group and an oxidizable hydroxyl group. The compound produced by oxidation has the absorption spectrum of a 17-oxo steroid in the Zimmermann reaction. The behaviour of the compound in three different types of chromatographic procedure is similar to that of authentic testosterone. Further chromatographic and spectroscopic evidence has shown that testosterone is the main compound in the final eluate from paper. In the present method a further gas-liquid-chromatographic step is generally used after paper chromatography and therefore it may be concluded that the method is reasonably specific.

In the present work, the results of experiments on enzymic hydrolysis have agreed with previous findings; the amount of testosterone recovered was increased slightly by prolonged incubation, by increased quantities of enzyme and by abolishing the effect of the endogenous inhibitor of $\beta$-glucuronidase known to be present in urine (Marsh, 1963). In the present procedure, simple acid hydrolysis was the method of choice for routine analysis. All other published methods have employed enzymic hydrolysis. The capacity of the present method to separate testosterone from large amounts of impurities is also shown by its ability to estimate testosterone in pregnancy urine. The similarity of the results obtained with acid and with enzyme hydrolysis by using a $\beta$-glucuronidase preparation suggests that the testosterone conjugate in human urine is mainly the glucuronide. This is in agreement with the findings of Camacho \& Migeon (1964) and others.

The accuracy and precision of the present method make the estimation of recoveries in all determinations by added internal standards unnecessary. However, the estimates obtained by gas-liquid chromatography could be corrected by the recoveries obtained from added internal radioactive standards. The results of the present investigation also show that the recoveries obtained with one method of detection may not agree with those obtained with another. Thus from the results of the present investigation it would not be justifiable to correct the estimates obtained with the microZimmermann reaction for the losses observed with added radioactive testosterone as in the method of Rosner et al. (1965). The fact that the estimates obtained by gas-liquid chromatography on replicates of material used for determinations by the
Zimmermann reaction were always higher suggests that impurities from the paper may have interfered in the Zimmermann reaction. Thus gas-liquid chromatography is probably the procedure of choice. A cause of the higher results obtained with some other methods (Tables 3 and 4) may be due to the incomplete separation of testosterone from other closely related compounds such as epitestosterone.

The colour reaction with vanillin in ethanolic sulphuric acid developed in the present investigation differs from that of Allen, Hayward \& Pinto $(1950)$ in that little or no colour is obtained with $3 \beta$-hydroxyandrost-5-en-17-one. Several methods for urinary testosterone have used the colour reaction described by Allen et al. (1950) with some modifications (Zurbrügg et al. 1965; Lim \& Dingman, 1965). This difference in the colour produced with $3 \beta$-hydroxyandrost-5-en-17-one may, in part, be due to the presence of an aldehyde, since G. Ittrich (personal communication) has obtained similar results with formaldehyde in place of vanillin.

The modification of the Girard reaction used in the present work is based on the procedure of Teitelbaum (1958) for unstable aldehydes and ketones that was adapted to steroids by Taylor (1958), whose findings were confirmed and extended by Lindner (1960). The present modification of the Girard separation avoids the harsh conditions of the original method, which may destroy some labile steroids and acetylate others. The derivatives of the saturated ketones in the original method are hydrolysed by dilute acid; the Girard complexes of the 'conjugated ketones' require considerably higher concentrations of acid for hydrolysis (Fieser \& Fieser, 1959). However, in the modified Girard separation the derivatives of the 'conjugated ketones' are easily split by aqueous formaldehyde. To release the saturated ketones, acid hydrolysis is still required.

In the present investigation, a considerable increase in the quantity of Girard reagent $T$ and also in the quantity of the catalyst, Amberlite IRC-50, was necessary to achieve quantitative results with crude urinary extracts; the resin also required activation by washing with acid. The separation of the 'conjugated-ketone' fraction from the nonketonic fraction and the bulk of the saturated ketonic components simplifies the subsequent separation procedures necessary to obtain a pure compound. In the present modification of the Girard separation it was found that testosterone could be extracted with benzene or light petroleum (b.p. $60-80^{\circ}$ ) almost as effectively as with ethyl acetate. This evidence suggests that the corticosteroids that can be obtained in the 'conjugatedketone' fraction could be extracted with chloroform or ethyl acetate after the removal of testosterone 
and compounds of similar polarity. It seems likely therefore that procedures similar to that described above for testosterone estimation could be used to simplify the estimation of many hormonally active neutral steroids. Such a procedure has already been used by Ismail \& Harkness (1966) in the first isolation of progesterone from human pregnancy urine.

A. A. A. I. is indebted to the Government of the United Arab Republic for financial support. The help of Professor R. B. Fisher and Dr J. A. Loraine is gratefully acknowledged.

\section{REFERENCES}

Allen, W. M. (1950). J. clin. Endocrin. 10, 71.

Allen, W. M., Hayward, S. J. \& Pinto A. (1950). J. clin. Endocrin. 10, 54.

Astle, M. J. (1957). In Ion Exchangers in Organic and Biochemistry, p. 662. Ed. by Calmon, C. \& Kressman, T. R. E. New York: Interscience Publishers Inc.

Brooks, C. J. W. \& Hanaineh, L. (1963). Biochem. J. 87, 151.

Brooks, R. V. (1964). Steroids, 4, 117.

Brooks, R. V. \& Giuliani, G. (1964). Steroids, 4, 101.

Brown, J. B. (1955). Biochem. J. 60, 185.

Brown, J. B., Bulbrook, R. D. \& Greenwood, F. C. (1957). J. Endocrin. 16, 41.

Bush, I. E. (1952). Biochem. J. 50, 370.

Camacho, A. M. \& Migeon, C. J. (1963). J. clin. Endocrin. 23, 301.

Camacho, A. M. \& Migeon, C. J. (1964). J. clin. Invest. 43, 1083.

Cathro, D. M., Cameron, J. \& Birchall, K. (1965). J. Chromat. 17, 362.

Dorfman, R. I. \& Shipley, R. A. (1956). Androgens, p. 59. London: Chapman and Hall.

Dulmanis, A., Coghlan, J. P., Wintour, M. \& Hudson, B. (1964). Aust. J. exp. Biol. med. Sci.42, 385.

Fieser, L. F. \& Fieser, M. (1959). Steroids, p. 449. New York: Reinhold Publishing Co.
Fowlis, A., Maggs, R. J. \& Scott, R. P. W. (1964). J. Chromat. 15, 471.

Futterweit, W., McNiven, N. L., Narcus, L., Lantos, C., Drosdowsky, M. \& Dorfman, R. I. (1963). Steroids, 1, 628.

Girard, A. \& Sandulesco, G. (1936). Helv. chim. Acta, 19, 1095.

Harkness, R. A. \& Fotherby, K. (1963). Biochem. J. 88, 308.

Horton, R., Shinsako, J. \& Forsham, P. H. (1965). Acta endocr., Kbh., 48, 446.

Ibayashi, H., Nakamura, M., Murakawa, S., Uchikawa, T., Tanioka, T. \& Nakao, K. (1964). Steroids, 3, 559.

Ismail, A. A. A. \& Harkness, R. A. (1965). Acta endocr., Kbh., 100 (Suppl.), 47.

Ismail, A. A. A. \& Harkness, R. A. (1966). Biochem. J. 98, $15 \mathrm{P}$.

Koenig, U. L., Melzer, F., Szego, C. M. \& Samuels, L. T. (1941). J. biol. Chem. 141, 487.

Lim, N. Y. \& Dingman, J. F. (1965). J. clin. Endocrin. 25, 563.

Lindner, H. R. (1960). Biochim. biophys. Acta, 38, 360.

Marsh, C. A. (1963). Biochem. J. 86, 77.

Menini, E. \& Norymberski, J. K. (1962). Biochem. J. 84, 195.

Menini, E. \& Norymberski, J. K. (1965). Biochem. J. 85, 1.

Rosner, J. M., Conte, N. F., Briggs, J. H., Chao, P. Y., Sudman, E. M. \& Forsham, P. H. (1965). J. clin. Endocrin. 25, 95.

Sandberg, D. H., Ahmad, N., Cleveland, W. W. \& Savard, K. (1964). Steroids, 4, 557.

Schubert, K. \& Frankenberg, G. (1964). Hoppe-Seyl. Z. 336, 91.

Schubert, K.\& Wehrberger, K. (1960). Naturwissenschaften, 47, 281.

Snedecor, G. W. (1952). Biometrics, 8, 85.

Sparagana, M. (1965). Steroids, 5, 773.

Taylor, W. (1958). Nature, Lond., 182, 1734.

Teitelbaum, C. L. (1958). J. org. Chem. 23, 646.

Vander Wiele, R. L., McDonald, P. C., Gurpide, E. \& Lieberman, S. (1963). Recent Progr. Hormone Res. 19, 275.

Vermeulen, A. \& Verplancke, J. C. M. (1963). Steroids, 2, 453.

Voigt, K. D., Volkwein, U. \& Tamm, J. (1964). Klin. Wschr. $42,642$.

Zurbrügg, R. P., Jacobs, R. D. B. \& Gardner, L. I. (1965). J. clin. Endocrin. 25, 315. 